\title{
ESTIMATION OF BALLISTIC PARAMETERS OF GUN PROPELLANTS THROUGH CLOSED VESSEL EXPERIMENT MODELING
}

\begin{abstract}
J. L. S. P. de Oliveiraa,
A. A. M. F. Filhob,

G. M. Platt ${ }^{c}$, and F. C. Peixotod

anstituto Militar de Engenharia - DE/5 - Praça General Tibúrcio, 80

- Praia Vermelha - Rio de Janeiro - RJ - 22290270

${ }^{\mathrm{b}} \mathrm{CTEx}$ - Instituto de Pesquisa e Desenvolvimento - Av. das

Américas, 28705 - Guaratiba - Rio de Janeiro - RJ - 23020470

'Universidade do Estado do Rio de Janeiro - IPRJ - Rua Alberto

Rangel, s/n - Vila Nova - Nova Friburgo - RJ - 28630050

'Instituto Militar de Engenharia - SE/5 - Praça General Tibúrcio, 80

- Praia Vermelha - Rio de Janeiro - RJ - 22290270 -

fpeixoto@ime.eb.br
\end{abstract}

\begin{abstract}
Closed vessels have being used for the regression of lumped ballistic parameters for decades. However, if material and energy balances are coupled with burning rate empirical correlations, several uncorrelated parameters can be estimated, which describe more accurately the thermochemical behavior of the gases generated, even if the chemical composition of the propellant is unknown (as when the propellant is aged, for instance). This research presents such approach leading to a system of differential equations which are integrated to produce a theoretical pressure profile in the vessel, highly dependent on the choice of empirical parameters. Such parameters are manipulated according to the Maximum Likelihood statistical procedure, which leads to the best set of parameters to describe the propellant.
\end{abstract}

Keywords: propellants, ballistic parameters, estimation, closed vessel

\section{NOMENCLATURE}

A parameter for the $\overline{\mathrm{Cp}}$ model, $\mathrm{J} / \mathrm{kg} . \mathrm{K}$

B parameter for the $\overline{\mathrm{Cp}}$ model, J/kg.K2

C parameter for the $\overline{\mathrm{Cp}}$ model, J.K/kg

$\mathrm{COV}$ variance-covariance matrix

$\frac{\mathrm{Cp}}{\mathrm{Cp}}$

$\overline{\mathrm{Cp}}$

D0

dQ

$\mathrm{dU}$

dW

$\frac{\mathrm{f}}{\mathrm{f}}$

$\mathrm{H}$

$\overline{\mathrm{H}}$

$\mathrm{k}$

M

$\mathrm{m}$

$\mathrm{P}$

Pmax maximum pressure achieved, $\mathrm{Pa}$

$\mathrm{R}$ gas universal constant, $\mathrm{J} / \mathrm{mol}$.K

$\mathrm{S} \quad$ superficial burning area, $\mathrm{m}^{2}$

$\mathrm{S}_{\mathrm{y}}{ }^{2} \quad$ variance estimator, $\mathrm{Pa}^{2}$

$\mathrm{T}$ temperature, $\mathrm{K}$

$\mathrm{t}$ time, $\mathrm{s}$

$\mathrm{V}$ volume, $\mathrm{m}^{3}$

$\mathrm{Z}$ heat capacity at constant $\mathrm{P}, \mathrm{J} / \mathrm{K}$

specific heat capacity, J/kg.K

propellant web, $\mathrm{m}$

increment of system's internal energy, J

increment of work performed, J

specific force, $\mathrm{J} / \mathrm{kg}$

enthalpy, J

specific enthalpy, $\mathrm{J} / \mathrm{kg}$

average molecular weight, $\mathrm{kg} / \mathrm{mol}$

mass, $\mathrm{kg}$

burnt volume fraction

\section{Greek Symbols}

$\alpha \quad$ burning law estimated parameter

$\beta \quad$ burning law estimated parameter, $\mathrm{m} / \mathrm{s} \cdot \mathrm{Pa}^{\alpha}$

$\Delta \quad$ load density, $\mathrm{kg} / \mathrm{m}^{3}$

$\Phi \quad$ sum of squared residuals, $\mathrm{Pa}^{2}$

$\eta \quad$ co-volume, $\mathrm{m}^{3} / \mathrm{kg}$

$\theta$ form factor

$\rho \quad$ density, $\mathrm{kg} / \mathrm{m}^{3}$

\section{Subscripts}

$0 \quad$ initial

g gas

s solid

\section{Superscripts}

298 temperature reference (298 K)

c calculated

e experimental

\section{INTRODUCTION}

Closed vessels have being used for the regression of ballistic parameters for the past six decades. They are employed, in most cases, to estimate lumped or comparative parameters like quickness or maximum pressure achieved. 
Additionally, they are employed as quality control tools, dictating whether the propellant (gun powder) is within established patterns or must be re-processed.

For that, a known mass of the propellant under study is put in the vessel (which is a robust pressure vessel); it is closed and the propellant is remotely ignited by a computer, which also performs the pressure data acquisition. Figure 1 shows an schematic view of the equipment, which can be considered, by all means, a chemical reactor.

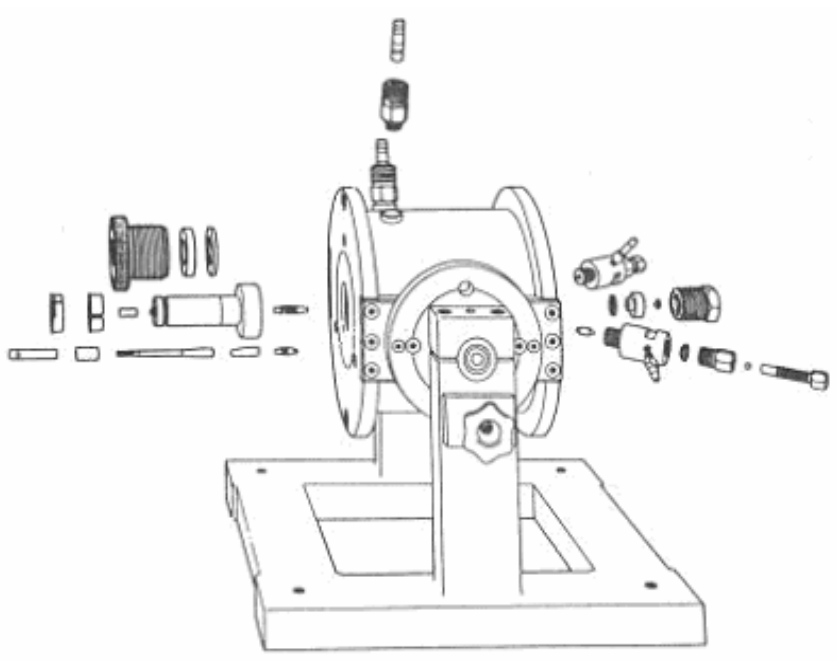

Figure 1. Schematic view of the Closed Vessel.

However, for the design and simulation of artefacts that use propellants (rifles, guns, rockets, mortars, howitzers and cannons), it would rather be of interest to use the thousands of pressure versus time points generated in each shot for the estimation of as many as ballistic (thermodynamic and kinetic) parameters as possible.

Some of these parameters can be calculated through thermodynamic procedures, as Hirschfelder-Sherman $(1942,1943)$ method. However, this approach requires the knowledge of the chemical composition of the propellant instead of using experimental information of a real shot. Besides, the propellant "ages" by loss of volatile components and, for the prediction of gun behavior, frequent chemical compositional analysis would be required, for which analytical methods are still not well established.

The present work is devoted to the development of two models for the functioning of the closed vessel: the first one, a most complete one, complies material and energy balances inside the vessel and results in a system with a differential equation for the time evolution of propellant mass and another one for the temperature; the second one, which is simpler, executes only a material balance and weaves an hypothesis on the temperature of the gases. Both models have their parameters estimated by maximum likelihood procedures and are analyzed in terms of its variances and co-variances.

\section{THEORY}

\section{Model with Energy Balance}

Even in this first model, that takes into account the energy balance, two hypotheses have to be used: the system is adiabatic (there is not enough time for thermal exchanges, due to the quick combustion dynamic) and an exothermic reaction of decomposition occurs within the vessel in the form:

$$
\text { Solid } \rightarrow \text { Gas + Energy }
$$

The second hypothesis [Eq. (1)] is a consequence of the fact that it is not possible or not of interest to describe the chemical composition of the gaseous products but only the thermochemical behavior of the gas phase.

By the first law of the thermodynamics, we have:

$$
\text { dQ dU } \square \mathrm{dW}
$$

respectively increments of heat inputs to the system, in its internal energy and of work performed by the system. Here and henceforth, every entity will be assumed to be in SI units. Once the vessel experiences no deformation and due to the adiabaticity:

$$
\text { dU } \quad 0
$$

where one can see that the energy envelope of the system is closed. Thus, the energy, in any instant, is distributed between solid (subscript s) and gas (subscript g) phases:

$$
\frac{\mathrm{dU}_{\mathrm{s}}}{\mathrm{dt}}+\frac{\mathrm{dU}_{\mathrm{g}}}{\mathrm{dt}}=0
$$


The unique information regarding energy production in the reaction is acquired through a Parr bomb, which measures enthalpy of reaction. So, it is convenient to relate energy and enthalpy variations:

$$
\frac{\mathrm{dU}}{\mathrm{dt}} \quad \frac{\mathrm{dH}}{\mathrm{dt}} \square \mathrm{P} \frac{\mathrm{dV}}{\mathrm{dt}} \square \mathrm{V} \frac{\mathrm{dP}}{\mathrm{dt}}
$$

where $\mathrm{P}$ stands for the pressure in the vessel, $\mathrm{V}$ for its volume, $\mathrm{H}$ for system enthalpy and $\mathrm{t}$ for the time since the ignition. The derivative of the enthalpy, for each subsystem ( $\mathrm{s}$ and $\mathrm{g}$ ) can be written as (Smith and Van Ness, 1993):

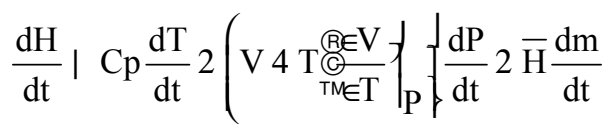

where $\mathrm{Cp}$ is the heat capacity at constant $\mathrm{P}, \overline{\mathrm{H}}$ is the specific enthalpy and $m$ the mass of each subsystem.

Denoting by $\overline{\mathrm{Cp}}_{\mathrm{s}}$ the specific heat capacity of the solid, one can be calculate its specific enthalpy from its reference value $\overline{\mathrm{H}}_{\mathrm{s}}^{-298}$ at $298 \mathrm{~K}$. Neglecting its thermal expansion coefficient and denoting its density by $\rho s$, we are left with:

$$
\begin{aligned}
& \frac{\mathrm{dU}_{\mathrm{s}}}{\mathrm{dt}} \quad \overline{\mathrm{Cp}}_{\mathrm{s}} \cdot \mathrm{m}_{\mathrm{s}} \frac{\mathrm{dT}}{\mathrm{dt}} \square \mathrm{P} \frac{1}{\mathrm{U}_{\mathrm{s}}} \frac{\mathrm{dm}_{\mathrm{s}}}{\mathrm{dt}} \square
\end{aligned}
$$

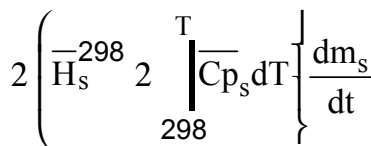

Analogous procedure, carried out for the gas phase, leads to:

$$
\begin{aligned}
& \frac{\mathrm{dU}_{\mathrm{g}}}{\mathrm{dt}} \square \mathrm{T} \stackrel{\S \mathrm{WV}_{\mathrm{g}}}{\odot \mathrm{CWT}} \cdot \frac{\mathrm{dP}}{{ }_{\mathrm{P}}} \mathrm{\frac { \textrm {dt } } { \mathrm { dt } }} \square \mathrm{P} \frac{\mathrm{dV}_{\mathrm{g}}}{\mathrm{dt}} \square \overline{\mathrm{Cp}}_{\mathrm{g}} \cdot \mathrm{m}_{\mathrm{g}} \frac{\mathrm{dT}}{\mathrm{dt}} \square
\end{aligned}
$$

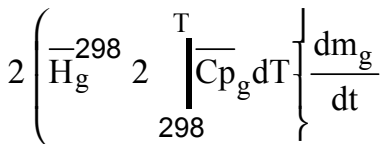

In ballistic studies, it is a common practice to adopt the equation of Nobel-Abel to describe P$\mathrm{V}-\mathrm{T}$ behavior of the gas phase (Vincent, 1987):

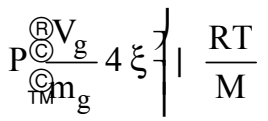

where $\eta$ is the co-volume and $M$ is the average molecular weight of the gas phase. This equation will be used to calculate the derivative of $\mathrm{V}$ with respect to $\mathrm{T}$ with $\mathrm{P}$ fixed, in Eq. (8). Once total mass and volume are constant, Eq. (9) can be used to calculate the time derivative of $\mathrm{P}$ [necessary in Eq. (8)] as a function of the time derivative of T:

$$
\begin{aligned}
& \frac{\mathrm{dP}}{\mathrm{dt}} \frac{\mathrm{RT}}{\mathrm{V}_{\mathrm{g}} \square \mathrm{Km}_{\mathrm{g}}} \llbracket \frac{1}{\mathrm{M}} \frac{\mathrm{dm}_{\mathrm{g}}}{\mathrm{dt}} \mathrm{u}
\end{aligned}
$$

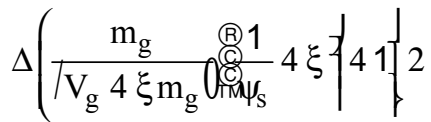

$$
\begin{aligned}
& \frac{\text { R.m }_{\mathrm{g}}}{\left.\mathrm{M} \backsim \mathrm{V}_{\mathrm{g}} \square \mathrm{Km}_{\mathrm{g}}\right] \mathrm{dt}}
\end{aligned}
$$

Combining Equations (7) to (10), one can express the time derivative of $\mathrm{T}$ as:

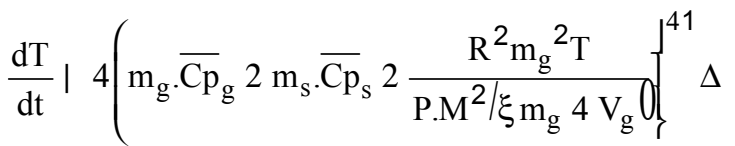

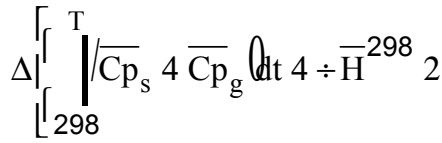

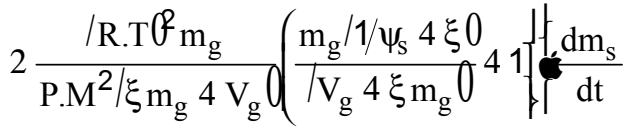

where ' $\overline{\mathrm{H}}^{298}$ is the enthalpy variation in the combustion reaction, measured, in standard conditions, by a Parr bomb. Much simpler, the rate of propellant consumption is given by Vielle/ Moraour/Saint-Robert law (Vincent, 1987; Moraour, 1947) as:

$$
\frac{\mathrm{dm}_{\mathrm{S}}}{\mathrm{dt}} \quad \square \mathrm{S} . \mathrm{k} . \mathrm{P}^{\mathrm{D}}
$$

where $\mathrm{S}$ is the superficial burning area and $\mathrm{k}$ and $\alpha$ are parameters subject to estimation procedures. Area $\mathrm{S}$ at any moment of the combustion reaction can be related to the remaining mass merely with 
geometric arguments. This treatment will not be carried out once we used ribbon shaped propellant (constant area). The last required models are those for the calorific capacities and will be used in the traditional form (Smith and Van Ness, 1993):

$$
\overline{\mathrm{Cp}} \quad \text { A } \square \text { B.T } \frac{\mathrm{C}}{\mathrm{T}^{2}}
$$

where parameters $\mathrm{A}, \mathrm{B}$ and $\mathrm{C}$ are considered known for the solid (they have small influence in the results and can be considered to be equal to the ones of thermoplastic polymers) and, for the gases, are subject of estimation. In this form, the set of parameters to be estimated in this model (and which describes the ballistic behavior - thermodynamic and kinetic - of the powder) is given by $\mathrm{k}, \alpha, \mathrm{A}_{\mathrm{g}}$, $\mathrm{B}_{\mathrm{g}}, \mathrm{C}_{\mathrm{g}}, \mathrm{M}$ and $\eta$.

The simulation of this model in terms of time evolution of $\mathrm{ms}$ and $\mathrm{T}$ is subject to initial conditions given by the mass of solid initially present in the vessel (ms0) and by the ambient temperature. Such can be done by any integration method; the present work has used Euler Method in its vectorial version with a time increment equal to the digital sampling of the equipment.

\section{Simplified Model}

In this second model, one admits that, since the ignition, the gas is in its adiabatic flame temperature (T0). That is justified by the enormous volume of gas generated in comparison with the initial air mass present in the vessel and due to the high reaction rates.

This model description is started by defining $\mathrm{D}$ as the propellant web which is a characteristic path that must be burnt for total consumption of the propellant grain: in a ribbon, the thickness; in a long pipe, the thickness of the wall; in a long cylinder, the diameter and so on. The remaining web fraction and the burnt volume fraction (v) will be denoted by $\mathrm{f}$ and $\mathrm{z}$, respectively:

$$
f(t) \quad \frac{D(t)}{D 0} \quad \text { and } \quad z(t) \quad \frac{v 0 \square v(t)}{v 0}
$$

where " 0 " denotes initial values for each entity.

It is a common practice to relate $\mathrm{z}$ and $\mathrm{f}$ with the so called form function:

$\mathrm{z} \quad(1 \square \mathrm{f})(1 \square \mathrm{Tf})$ where $\theta$ is the form factor, which is characteristic of each geometry and also obtained with geometric arguments (zero for ribbons, thickness-to-length ratio for pipes, unitary for long cylinders, etc).

At the end of burning, all the propellant mass is burnt to gaseous products, the pressure is at its maximum registered level (Pmax), the temperature is $\mathrm{T} 0$ and the gas fills the whole vessel volume (v) from which, Eq. (9) leads to:

$$
\frac{P \max }{\mathrm{I}} \overline{\mathrm{f}} \square \mathrm{P} \max . K
$$

where $\Delta$ is the load density of the bomb $(\mathrm{ms} 0 / \mathrm{V})$ and $\overline{\mathrm{f}}$ RT / $\mathrm{M}$ is the so called specific force, a very useful entity in the design of armaments and in propellants ballistic evaluation. In this format, linear fittings for Pmax/ $\Delta$ versus Pmax can be carried out with, at least, 3 shots at different load densities; $\overline{\mathrm{f}}$ is the linear coefficient and $\eta$ is the angular one.

In each individual shot, the dynamic information can be used, as the (nonlinear) fittings of the previous model, for the regression of parameters of combustion tax. In this model, because of its algebraic simplicity and in order to introduce a way to fit even $\theta$, the law of Vielle/ Moraour/Saint-Robert will be used in the following format, also available in literature:

$$
\mathrm{v} \quad \square \mathrm{D} 0 \frac{\mathrm{df}}{\mathrm{dt}} \quad \mathrm{E} \cdot \mathrm{P}^{\mathrm{D}}
$$

If the gas phase behaves as Eq. (9), we have:

$$
P(t) \searrow_{g}(t) \square m_{g}(t) K @ m_{g}(t) \bar{f}
$$

where $\mathrm{V}_{\mathrm{g}}$ is the volume of the gas and $\mathrm{m}_{\mathrm{g}}$ its mass, following the adopted notation ( $\mathrm{g}$ for gas $\mathrm{s}$ for solid). It is worth standing out that the time dependence will be suppressed by notation simplicity and once it is obvious which entities vary with time and which are (considered) constant.

Thus, once again because total volume and the mass are constant and shared by solid and gaseous phases and by the definition of $\mathrm{z}$, we have:

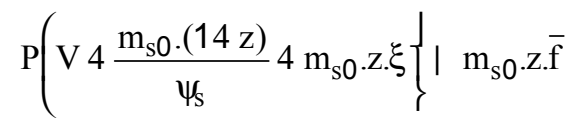




\section{CIÊNCIA/SCIENCE}

which leads to:

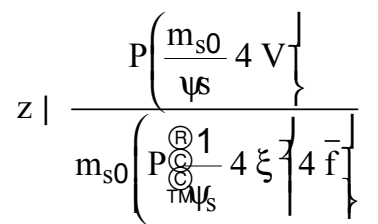

From Eq. (15), we have:

$$
f \frac{(T \square 1) r \sqrt{(T \square 1)^{2} \square 4 T(z \square 1)}}{2 T}
$$

Using Eq. (20) in (21) and taking its time derivative to include in Eq. (17), we are left with:

$$
\begin{aligned}
& \frac{\mathrm{dP}}{\mathrm{dt}} \frac{\mathrm{E}}{\mathrm{D} 0} \mathrm{P} \frac{\mathrm{D} \frac{\mathrm{k} 2 . \mathrm{P} \square \mathrm{K} 3\left[^{2}\right.}{\mathrm{K} 3|\mathrm{~K} 1 \square \mathrm{K} 2|} \mathrm{u}}{\mathrm{u}} \\
& \sqrt{(\mathrm{T} \square 1)^{2} \square 4 \mathrm{~T} \frac{\mathrm{K} 1 . \mathrm{P} \square \mathrm{K} 3}{\mathrm{~K} 2 \cdot \mathrm{P} \square \mathrm{K} 3}}
\end{aligned}
$$

with $\mathrm{K} 1=\mathrm{ms} 0 . \eta-\mathrm{V}, \mathrm{K} 2=\mathrm{ms} 0(1 / \rho \mathrm{s}-\eta)$ and $\mathrm{K} 3=\mathrm{ms} 0 \overline{\mathrm{f}}$ and to be integrated directly for a pressure profile, also by Euler's method, in its scalar version. Its worth saying that the choice of signal in Eq. (21) was made forcing the pressure to rise monotonically in Eq. (22). In this second model, only $\beta, \alpha$ and $\theta$ are, non-linearly, estimated.

\section{Maximum Likelihood Procedure}

In both models, pressures are generated by simulation (which is dependent of each model concerning parameters) on the same times of experimental samples and stocked in the vectorial variable Pc; its experimental equivalent will be denoted by Pe. Using a weight matrix $\mathrm{W}$ to give each experimental point a different importance, one can calculate the weighted sum of squared residuals as:

$$
\text { ) } \left.\left.\quad \underline{P}^{\mathrm{c}} \square \underline{\underline{P}}^{\mathrm{e}}\right] \underline{\underline{\mathrm{w}}} \underline{\underline{P}}^{\mathrm{c}} \square \underline{\underline{P}}^{\mathrm{e}}\right]
$$

The non-linear minimization of $\Phi$ with numerical parameter of each model manipulation is the method of the maximum likelihood (Britt and Luecke, 1973). Such manipulation was implemented, in this work, by a Newton-like algorithm, with a Hessian matrix BFGS update (Edgar and Himmelblau, 1988).

\section{RESULTS AND DISCUSSION}

The procedures described for simulation and regression were executed for each model, being the simpler model fitted in two steps: first, a linear one, with 3 shots being required, than a non-linear one.

The first model results are shown in Tab. 1 and the second, in Tab. 2, where the error (after the symbol \pm ) must be understood as the standard deviation of the related quantity. Model variance estimator is denoted by $\mathrm{S}_{\mathrm{y}}{ }^{2}$ and the variancecovariance matrix by COV; once it is a $7 \times 7$ entity, it is depicted at the end of this work.

Figure 2 represents the confidence region of the parameters estimated in the first fitting (linear) and Fig. 3 the second one (nonlinear), both of the second model. The first model, for making use of 7 parameters, turns the representation of related confidence regions into an impossible task (7-D ellipsoids). Figure 4 shows a typical modelto-data adherence:

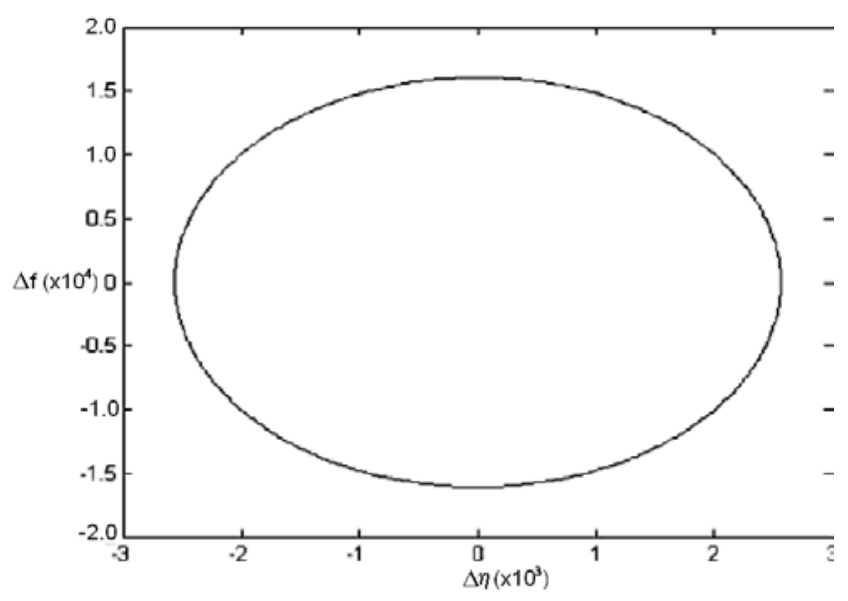

Figure 2. Confidence region (level 99\%) of $\eta$ and (second model).

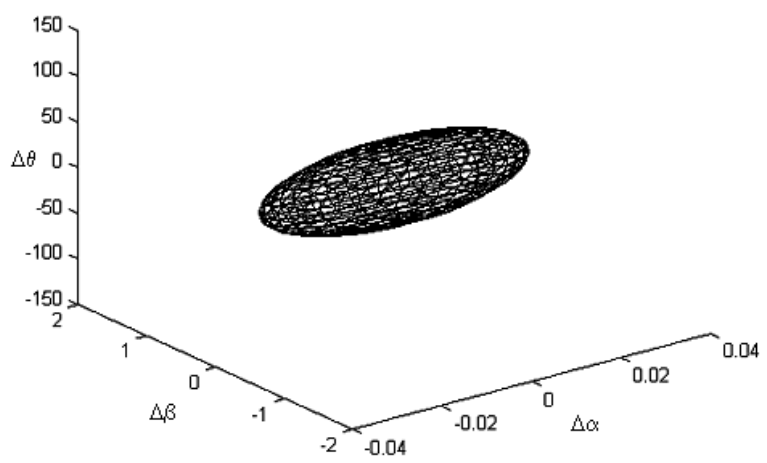

Figure 3. Confidence region (level 99\%) of $b$, a e q (second model). 


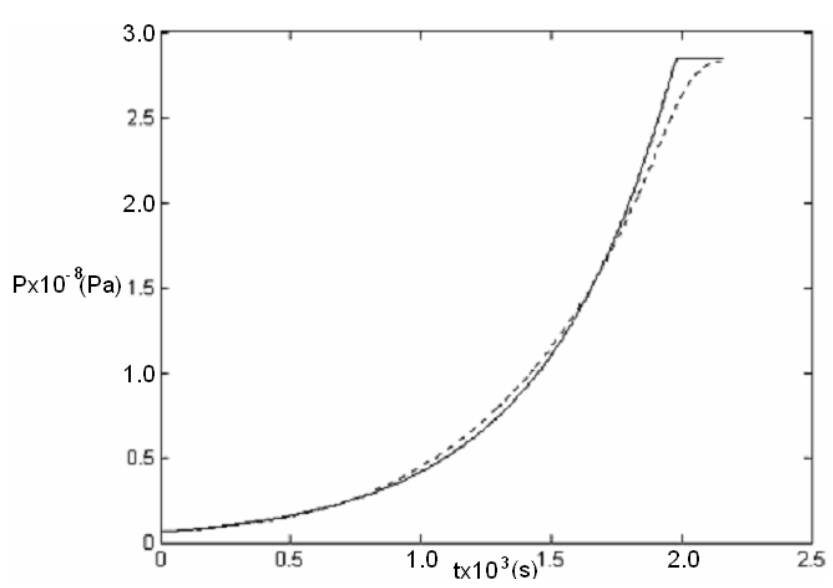

Figure 4. Data fitting (typical result).

Table 1. First model fitting.

\begin{tabular}{|c|l|}
\hline Entity & \multicolumn{1}{|c|}{ Value } \\
\hline $\mathrm{k}$ & $0.0387 \pm 0.1218 \mathrm{~m} / \mathrm{s}$ \\
\hline$\alpha$ & $0.4567 \pm 0.1143$ \\
\hline $\mathrm{M}$ & $0.0288 \pm 0.0601 \mathrm{~kg} / \mathrm{mol}$ \\
\hline $\mathrm{Ag}$ & $1.197310^{-7} \pm 211.2399 \mathrm{~J} / \mathrm{kg} . \mathrm{K}$ \\
\hline $\mathrm{Bg}$ & $1.2606 \pm 2.4832 \mathrm{~J} / \mathrm{kg} . \mathrm{K}^{2}$ \\
\hline $\mathrm{Cg}$ & $0.9752 \pm 8.746510^{8} \mathrm{~J} . \mathrm{K} / \mathrm{kg}$ \\
\hline$\eta$ & $9.55210^{-4} \pm 0.0014 \mathrm{~m}^{3} / \mathrm{kg}$ \\
\hline $\mathrm{S}_{\mathrm{y}}{ }^{2}$ & $2.253810^{13} \mathrm{~Pa}^{2}$ \\
\hline
\end{tabular}

Table 2. Second model fitting

\begin{tabular}{|c|c|c|}
\hline Entity & \multicolumn{2}{|l|}{ Value } \\
\hline$\eta$ & \multicolumn{2}{|l|}{$0.0012 \pm 1.378110^{-4} \mathrm{~m}^{3} / \mathrm{kg}$} \\
\hline $\bar{f}$ & \multicolumn{2}{|l|}{$(107.73 \pm 2.8678) 10^{4} \mathrm{~J} / \mathrm{kg}$} \\
\hline$\alpha$ & \multicolumn{2}{|l|}{$0.9196 \pm 1.067310^{-4}$} \\
\hline$\beta$ & \multicolumn{2}{|c|}{$(232.03 \pm 8.0821) 10^{-11} \mathrm{~m} / \mathrm{s} \cdot \mathrm{Pa}^{\alpha}$} \\
\hline$\theta$ & \multicolumn{2}{|c|}{$0.0296 \pm 0.0131$} \\
\hline$\underline{\underline{\mathrm{COV}}}$ & {$\left[\begin{array}{cc}1.139210^{-8} & 5.57310^{-15} \\
5.57310^{-15} & 6.53210^{-21} \\
-9.767810^{-7} & -1.045710^{-12}\end{array}\right.$} & $\begin{array}{l}-9.767810^{-7} \\
-1.045710^{-12} \\
-9.767810^{-4}\end{array}$ \\
\hline $\mathrm{S}_{\mathrm{y}}^{2}$ & \multicolumn{2}{|l|}{$2.047210^{13} \mathrm{~Pa}^{2}$} \\
\hline
\end{tabular}

\section{CONCLUSIONS}

Two models were built for the description of a typical Closed Vessel experiment; the first one takes into account the energy balance and the other, a simpler one, considers that the gaseous mixture is, since the ignition, at the adiabatic flame temperature. Both are constituted of dynamic balances in the form of differential equations, with obvious initial conditions. Their simulations were carried out by Euler's method and related results were statistically compared to experimental data, being ballistic parameters manipulated by the method of the maximum likelihood.

Both models had shown high adherence to the experimental data; however, the most complete model showed prohibitive uncertainties associated to its parameters, as it can be noticed in its variances and covariances matrix. This model happens to describe in a more complete way the thermodynamic behavior of the gaseous products, although myopically. The use of equations of state more adequate for higher pressures, such as Peng-Robinson, Redlich-Kwong or Virial can diminish the uncertainties. This is being done by the authors, but is beyond the scope of the present work.

\section{ACKNOWLEDGEMENTS}

Fernando Cunha Peixoto, acknowledges the financial support by FAPERJ Foundation and CNPq Concil.

\section{REFERENCES}

Britt, H. I., Luecke, R. H., 1973, Estimation of Parameters in Nonlinear, Implicit Models, Technometrics, Vol. 15, No., 2, pp. 233-247.

Edgar, T. F. and Himmelblau, D. M., 1988, Optimization of Chemical Processes, McGraw Hill, Inc., New York.

Hirschfelder, J. O. and Sherman, J., Simple Calculation of Thermochemical Properties for Use in Ballistics NDRC A-101, OSRD 935, October, 1942 (SPIA Abstract No. 0303A); ibid., NDRC A101 (addenda), OSRD 935 (addenda) (OSRD1300, A-67M-A-70M), March 1943 (SPIAAbstract No. 0303B).

Moraour, H., 1947, Poudres et explosives, Paris, Presse Univ.

Smith, J. M. and Van Ness, H. C., 1993, Introduction to Chemical Engineering Thermodynamics, McGraw Hill, Inc., New York.

Vincent, R., 1987, Textbook of Ballistics and Gunnery, Volume One, Her Majesty's Stationery Office, London.

APPENDIX - Variance-Covariance Matrix of the First Model

$\underline{\underline{\mathrm{COV}}}=\left[\begin{array}{ccccccc}0.0148 & -0.0139 & 0.0071 & 7.414 & 0.2941 & 1.0537 .10^{8} & 1.2022 .10^{-4} \\ -0.0139 & 0.0131 & -0.0064 & -6.2631 & -0.2691 & -9.9552 .10^{7} & -1.0272 .10^{-4} \\ 0.0071 & -0.0064 & 0.0036 & 4.1285 & 0.1488 & 4.8387 .10^{7} & 7.1951 .10^{-5} \\ 7.414 & -6.2631 & 4.1285 & 4.4622 .10^{4} & 167.2035 & 4.9351 .10^{10} & 0.0940 \\ 0.2941 & -0.2691 & 0.1488 & 167.2035 & 6.1664 & 2.0377 .10^{9} & 0.0029 \\ 1.0537 .10^{8} & -9.9552 .10^{7} & 4.8387 .10^{7} & 4.9351 .10^{10} & 2.0377 .10^{9} & 7.6502 .10^{17} & 7.5904 .10^{5} \\ 1.2022 .10^{-4} & -1.0272 .10^{-4} & 7.1951 .10^{-5} & 0.0940 & 0.0029 & 7.5904 .10^{5} & 1.8487 .10^{-6}\end{array}\right]$

